\title{
Original Article \\ MYOCARDIAL DYSFUNCTION IN CHILDREN WITH NEPHROTIC SYNDROME, A TISSUE DOPPLER STUDY
}

\author{
Laila Rasslan Abd Elaziz' ${ }^{1}$ Heba Mohammed Abouzeid ${ }^{1}$, Khalifa Younes Abu Fares ${ }^{2}$ \\ 1Pediatric Department, Faculty of Medicine, Zagazig University, Zagazig, Egypt \\ 2Pediatric Department, Faculty of Medicine, Al-Mergeb University, Libya
}

CorrespondingAuthor:

Khalifa Younes Abu Fares

Faculty of Medicine - Al-

Mergeb University- Libya

abuliasyons47@gmail.com

\section{Submit Date 2019-02-20 \\ Revise Date 2019-03-13 \\ Accept Date 2019-03-14}

\begin{abstract}
Background: The prevalence of chronic kidney disease (CKD) has increased steadily. Mortality and morbidity are seen more frequently in CKD compared to in healthy subjects. Cardiovascular events are the most frequent cause of mortality and morbidity in this patient group.

Objectives: To assess the presence of fQRS in children with NS and to evaluate the relationship between fQRS and myocardial functions.

Patients \& Methods: 30 children with nephrotic syndrome and 30 apparently healthy children were enrolled in the study. All patients in this study were subjected to:

Full history taking, full clinical examination and laboratory investigations; (BUN), creatinine, albumin, calcium, phosphorus, LDL, HDL, triglycerides and $24 \mathrm{~h}$ urine collection for protein in urine. ECG and Echocardiography was performed to detect early pathological problems. Tissue doppler imaging was used to detect changes occurring in the heart with nephrotic syndrome.

Patient group was subdivided in to 2 groups according to presence of FQRS in ECG.
\end{abstract}

Results: fQRS was present in $56.7 \%$ of patient group. There was significant increase in systolic and diastolic blood pressure in patient with FQRS in ECG. There was no statistically significant differences between tissue doppler parameter and Tie index with FQRS except for Em wave. By univariate analysis for patient with FQRS and all parameter, FQRS was presented with increase in systolic and diastolic blood pressure, and in patient with systolic dysfunction (decrease FS\%), and in patient with diastolic dysfunction (E').

Conclusions: NS children generally have a high risk of cardiovascular complications. The present study revealed that fQRS determined using ECG, an economic and easily accessible technique, can be used as an early marker of myocardial function impairment in this patient group.

Keywords Myocardial dysfunction, A tissue doppler study.

\section{INTRODUCTION}

$\mathrm{T}$ The prevalence of chronic kidney disease (CKD) has increased steadily. Mortality and morbidity are seen more frequently in CKD compared to in healthy subjects. Cardiovascular events are the most frequent cause of mortality and morbidity in this patient group ${ }^{[1]}$.

Nephrotic syndrome (NS) is a condition characterized by severe proteinuria, hypoalbuminemia as well as dyslipidemia ${ }^{[2]}$.
More cardiovascular events are seen in NS patients than in the normal population ${ }^{[3]}$. The main reasons for these increased cardiovascular events are thought to be inflammation cascade activation due to proteinuria and malnutrition [4].

The QRS complex represents the electrical depolarization of ventricular myocardium. Abnormal electrical conduction leads to widening of the QRS complex. The block of www.zumj.journals.ekb.eg 


\section{Laila et al}

one of the bundle branches results in a typical bundle branch block pattern. A QRS complex that cannot be classified as bundle branch block due to an atypical configuration is called nonspecific intraventricular conduction delay or pre-excitation type Wolff-Parkinson-White. If the QRS complex has normal duration and contains notched $\mathrm{R}$ or $\mathrm{S}$ waveS, various RsR' patterns in at least 2 contiguous ECG leads is called a fragmented QRS (fQRS) ${ }^{[5]}$.

Fragmented QRS (fQRS) includes various RSR' patterns with different morphologies of the QRS complexes with or without the Q wave on a resting 12-lead ECG. Various RSR' patterns include an additional $R$ wave ( $R$ ') or notching in the nadir of the $\mathrm{S}$ wave, or the presence of $>1 R^{\prime}$ (fragmentation) in 2 contiguous leads, corresponding to a major coronary artery territory ${ }^{[6]}$. Studies to date have shown that presence of fQRS is associated with a rise in cardiovascular event incidence and cardiovascular mortality and morbidity. This association is thought to stem from myocardial scarring, ventricular arrhythmia and structural cardiac defects ${ }^{[7],[8]}$.

If QRS duration is prolonged, the proper nomenclature is wide fragmented QRS (wfQRS). The underlying pathophysiologies are manifold and include myocardial scars induced by ischemic heart disease, myocardial fibrosis due to other diseases, primary cardiac pathologies as well as systemic diseases with cardiac involvement. Pathologies on the cellular level, such as ion channel dysfunctions, also correlate with fragmented QRS. Besides the diagnostic relevance, fragmented QRS is known to have prognostic properties, for example in identifying high risk patients with coronary artery disease, cardiomyopathy, Brugada syndrome and acquired long QT syndrome; however, fQRS may also be detected in ECGs of healthy individuals ${ }^{[5]}$.

fQRS is a novel ECG marker with more sensitivity and less specificity than $Q$ wave. A combination of fQRS with Q wave in a 12-lead ECG results in up to $74 \%$ sensitivity and $92 \%$ specificity ${ }^{[9]}$. Classically, some echocardiographic parameters such as ejection fraction, peak systolic mitral annular velocity and rate of early and late mitral inflow velocities have been used to analyze systolic and diastolic myocardial functions. However, in some conditions these indices do not accurately reflect myocardial functions. The myocardial performance (Tei) index was first developed by Tei et al. ${ }^{[10]}$ to evaluate combined myocardial systolic and diastolic function. Several studies have shown that the Tei index is a more reliable parameter in the evaluation of systolic and diastolic function than classic echocardiographic indices ${ }^{[11]}$.

\section{PATIENTS AND METHODS}

This case control and cross section study was carried out in Pediatric Nephrology Unit and Cardiology Units at Zagazig University Hospital during the period from March to October 2018.

The study was done after taken approval from Institute Research Board of faculty of medicine, Zagazig University (IRB) and after All subjects' parents gave informed written consent to participate in the study.

The study included 60 children divided into two groups.

1- $\quad$ The first group thirty children with nephrotic syndrome twenty-three male and seven female ranged age from three to fifteen years old from Pediatric Nephrology Unit. we divided the patient's group into two subgroups according to presence or absence of fQRS in ECG into two subgroups:

- FQRS Positive: included 17 patients with fQRS in ECG. They were ...13 males, and ...4 females, their ages ranged from 5 to 12 years...

- FQRS Negative: included 13 patients with normal ECG. They were 10 males and 3 females, their ages ranged from 4 to 15 years.

2- The second group: thirty apparently healthy children, eleven female and nineteen male ranged age from three to fifteen years matched to cases regarding to age and sex

. All patients in this study were subjected to:

Full history taking. „Full clinical examination.,..Laboratory investigations: Blood urea nitrogen, creatinine, albumin, Calcium, 
phosphorus, Low density lipoprotein (LDL), high density lipoprotein (HDL), triglycerides and 24h urine collection for protein in urine.,, Electrocardiography.

Echocardiography was performed to detect early pathological problems.

Tissue doppler imaging was used to detect changes occur in the heart with nephrotic syndrome

Inclusion criteria: Children with NS,

Exclusion criteria: 1. Patients with a history of malignancy, findings of active infection or inflammation .2. Patients with significant organic heart disease 3. Patients with non-ischemic dilated cardiomyopathy.4.
Patients with bundle-branch block (left bundle-branch block, incomplete or complete right bundle-branch block) or intraventricular conduction delay (duration of QRS >120 ms) on ECG .5. Patients with permanent pacemakers, were excluded from the study The work has been carried out in accordance with The Code of Ethics of the World Medical Association (Declaration of Helsinki) for studies involving humans.

\section{RESULTS}

There is no statistically significant difference in Age \& sex and in anthroprometric and vital sign in both studied groups

Table 1 Bivariate analysis of presence FQRS with clinical parameter.

\begin{tabular}{|c|c|c|c|c|}
\hline & FQRS & Mean & Std. Deviation & $\mathbf{P}$ \\
\hline \multirow[t]{2}{*}{ Age } & YES & 5.8522 & 3.48371 & \multirow[t]{2}{*}{0.587} \\
\hline & NO & 6.2649 & 3.56388 & \\
\hline \multirow[t]{2}{*}{ Sex } & YES & Male female & $\begin{array}{c}15 \\
8\end{array}$ & \multirow[t]{2}{*}{0.52} \\
\hline & NO & $\begin{array}{c}\text { Male } \\
\text { Female }\end{array}$ & $\begin{array}{l}27 \\
10\end{array}$ & \\
\hline \multirow[t]{2}{*}{ HR } & YES & 98.9130 & 8.27325 & \multirow[t]{2}{*}{0.245} \\
\hline & NO & 96.3243 & 8.30680 & \\
\hline \multirow[t]{2}{*}{ SBP } & YES & 118.1739 & 4.55923 & \multirow[t]{2}{*}{$0.036 *$} \\
\hline & NO & 111.9459 & 3.43952 & \\
\hline \multirow[t]{2}{*}{ DBP } & YES & 79.6957 & 5.48083 & \multirow[t]{2}{*}{$0.03 *$} \\
\hline & NO & 70.9459 & 4.05480 & \\
\hline \multirow[t]{2}{*}{ BMI } & YES & 21.4478 & 1.40837 & \multirow[t]{2}{*}{0.290} \\
\hline & NO & 21.0405 & 1.45152 & \\
\hline
\end{tabular}


Table 2 Bivariate analysis of presence of FQRS with Laboratory parameter.

\begin{tabular}{|c|c|c|c|c|}
\hline & FQRS & Mean & Std. Deviation & $\mathbf{P}$ \\
\hline \multirow[t]{2}{*}{ BUN (mg/dl) } & YES & 13.8394 & 7.83809 & \multirow[t]{2}{*}{0.372} \\
\hline & NO & 11.5615 & 5.13815 & \\
\hline \multirow[t]{2}{*}{$\mathrm{Cr}$ (mg/dl) } & YES & .3906 & .22612 & \multirow[t]{2}{*}{0.103} \\
\hline & NO & .2631 & .17342 & \\
\hline \multirow[t]{2}{*}{ CA (mg/dl) } & YES & 8.0224 & .51155 & \multirow[t]{2}{*}{0.109} \\
\hline & NO & 8.3308 & .49932 & \\
\hline \multirow[t]{2}{*}{$P(\mathrm{mg} / \mathrm{dl})$} & YES & 5.0482 & 1.45949 & \multirow[t]{2}{*}{0.381} \\
\hline & NO & 4.5900 & 1.29006 & \\
\hline \multirow[t]{2}{*}{ Albumin (g/dl) } & YES & 2.6235 & .74713 & \multirow[t]{2}{*}{0.582} \\
\hline & NO & 2.7638 & .57182 & \\
\hline \multirow[t]{2}{*}{ Protein urea/24h (mg/dl) } & YES & 2028.6231 & 1449.79584 & \multirow[t]{2}{*}{0.848} \\
\hline & NO & 1435.5202 & 1431.42908 & \\
\hline \multirow[t]{2}{*}{ LDL (mg/dl) } & YES & 142.0588 & 46.80741 & \multirow[t]{2}{*}{0.128} \\
\hline & NO & 119.0000 & 28.24594 & \\
\hline \multirow[t]{2}{*}{ HDL (mg/dl) } & YES & 51.9412 & 8.99632 & \multirow[t]{2}{*}{0.533} \\
\hline & NO & 53.7692 & 6.02984 & \\
\hline \multirow[t]{2}{*}{ TG (mg/dl) } & YES & 210.7647 & 77.63096 & \multirow[t]{2}{*}{0.311} \\
\hline & NO & 179.1538 & 72.02181 & \\
\hline
\end{tabular}

Table 3 Bivariate analysis of presence of FQRS and ECHO Parameter

\begin{tabular}{|c|c|c|c|c|}
\hline & FQRS & Mean & Std. Deviation & $\mathbf{P}$ \\
\hline \multirow[t]{2}{*}{ MPA mm } & YES & $\mathbf{1 7 . 9 7 8 3}$ & 3.20978 & \multirow[t]{2}{*}{0.955} \\
\hline & NO & $\mathbf{1 7 . 9 2 9 7}$ & 3.19955 & \\
\hline \multirow[t]{2}{*}{ RPA mm } & YES & 8.4609 & 1.96254 & \multirow[t]{2}{*}{0.793} \\
\hline & NO & 8.3297 & 1.81779 & \\
\hline \multirow[t]{2}{*}{ LPA mm } & YES & 8.1217 & 1.75938 & \multirow[t]{2}{*}{0.829} \\
\hline & NO & 8.0216 & 1.72404 & \\
\hline \multirow[t]{2}{*}{ AO mm } & YES & 22.9957 & 4.45140 & \multirow[t]{2}{*}{0.290} \\
\hline & NO & 21.9189 & 3.34098 & \\
\hline \multirow[t]{2}{*}{ LA mm } & YES & 26.7609 & 5.50741 & \multirow[t]{2}{*}{0.517} \\
\hline & NO & 25.8297 & 5.30424 & \\
\hline \multirow[t]{2}{*}{ IVS mm } & YES & 8.3348 & 2.27448 & \multirow[t]{2}{*}{0.017} \\
\hline & NO & 7.7676 & 1.92371 & \\
\hline \multirow[t]{2}{*}{ PW mm } & YES & 8.5957 & 2.24185 & \multirow[t]{2}{*}{0.868} \\
\hline & NO & 8.4865 & 2.51948 & \\
\hline \multirow[t]{2}{*}{ TAPSE $\mathrm{mm}$} & YES & 21.0304 & 3.51444 & \multirow[t]{2}{*}{0.487} \\
\hline & NO & 20.3946 & 3.36336 & \\
\hline \multirow[t]{2}{*}{ LVDD mm } & YES & 38.0957 & 6.31517 & \multirow[t]{2}{*}{0.994} \\
\hline & NO & 38.0838 & 6.26585 & \\
\hline \multirow[t]{2}{*}{ LVSD mm } & YES & 23.3348 & 4.96786 & \multirow[t]{2}{*}{0.611} \\
\hline & NO & 22.7324 & 4.07452 & \\
\hline
\end{tabular}


Table 4 Bivariate analysis of presence of FQRS with systolic and diastolic conventional.

\begin{tabular}{|c|c|c|c|c|}
\hline & $\begin{array}{c}F \\
\text { QRS }\end{array}$ & Mean & Std. Deviation & $\mathbf{P}$ \\
\hline \multirow[t]{2}{*}{ EF\% } & YES & 68.9743 & 6.71166 & \multirow[t]{2}{*}{0.069} \\
\hline & NO & 71.7676 & 4.94526 & \\
\hline \multirow[t]{2}{*}{ FS\% } & YES & $\mathbf{3 7 . 9 4 3 5}$ & 5.15151 & \multirow[t]{2}{*}{0.027} \\
\hline & No & 43.5543 & 6.42670 & \\
\hline \multirow[t]{2}{*}{ E wave } & YES & 85.0043 & 21.79231 & \multirow[t]{2}{*}{0.398} \\
\hline & NO & 90.4541 & 25.44042 & \\
\hline \multirow[t]{2}{*}{ A wave } & YES & 53.7348 & 10.93392 & \multirow[t]{2}{*}{0.177} \\
\hline & NO & 59.3486 & 17.66830 & \\
\hline \multirow{2}{*}{$\begin{array}{c}\text { DT OF E wave } \\
\text { ms }\end{array}$} & YES & 89.5652 & 20.22336 & \multirow[t]{2}{*}{0.918} \\
\hline & NO & 90.1351 & 20.94028 & \\
\hline
\end{tabular}

Table (5): Bivariate analysis of presence of FQRS and Tissue Doppler parameter and Tie index

\begin{tabular}{|c|c|c|c|c|}
\hline & F QRS & Mean & Std. Deviation & $\mathbf{P}$ \\
\hline \multirow[t]{2}{*}{$S$ wave } & YES & 8.2391 & 1.61210 & \multirow[t]{2}{*}{0.100} \\
\hline & NO & 9.1622 & 2.31869 & \\
\hline \multirow[t]{2}{*}{ E m } & YES & 13.3522 & 3.63166 & \multirow[t]{2}{*}{ 0.014* } \\
\hline & NO & 15.8027 & 3.66822 & \\
\hline \multirow[t]{2}{*}{ A $\mathbf{m}$} & YES & 7.4913 & 1.81306 & \multirow[t]{2}{*}{0.360} \\
\hline & NO & 8.1622 & 3.17161 & \\
\hline \multirow[t]{2}{*}{ A (ms) } & YES & 380.0000 & $\mathbf{5 3 . 4 8 9 1 7}$ & \multirow[t]{2}{*}{0.311} \\
\hline & NO & 367.2432 & 42.61938 & \\
\hline \multirow[t]{2}{*}{ B (ms) } & YES & 249.3913 & 26.48969 & \multirow[t]{2}{*}{0.734} \\
\hline & NO & 245.9892 & 42.79608 & \\
\hline \multirow[t]{2}{*}{ A-B/B } & YES & .5260 & .15468 & \multirow[t]{2}{*}{0.951} \\
\hline & NO & .5231 & .18350 & \\
\hline
\end{tabular}

\section{DISCUSSION}

Nephrotic syndrome is primarily a pediatric disorder and is 15 times more common in children than adults. The incidence is 2$3 / 100,000$ children per year, and the vast majority of affected children will have steroidsensitive minimal change disease ${ }^{[16]}$. The term nephrotic syndrome is applicable to any condition with heavy proteinuria (> 40 $\mathrm{mg} / \mathrm{m} 2 /$ hour or protein/creatinine ratio $>2$ ), hypoproteinemia (plasma albumin $<2.5 \mathrm{gm} / \mathrm{dl}$ ), edema and hyperlipidemia [17]. Tubular abnormalities seen in Minimal-Change
Nephrotic Syndrome (MCNS) include protein droplets, lipid accumulation, focal calcification and disruption by extruded casts ${ }^{[18]}$. NS is a clinical picture accompanied by biochemical (hypoalbuminemia, hyperlipidemia) and metabolic (edema) abnormalities caused by massive proteinuria ${ }^{[2]}$. Incidence of cardiovascular events increases in the NS patient group compared to the normal population. Intestinal edema developing secondary to massive proteinuria-associated hypoalbuminemia reduces nutrient absorption and leads to malnutrition and activation of www.zumj.journals.ekb.eg 


\section{Laila et al}

inflammatory cascade. Various inflammatory mediators (such as TNF $\alpha$ ) exhibit a negative inotropic effect on the myocardium ${ }^{[19]}$. In this way, malnutrition and inflammation lead to an increase in cardiovascular events incidence in the NS patient group. Thrombosis frequency is known to increase in this patient group. In particular, deep vein thrombosis and pulmonary embolism secondary to this cause impairment in right ventricular functions [3]. Hyperlipidemia, one of the diagnostic criteria for NS, is known to be a cardiovascular events risk factor. Therefore, dyslipidemia, which is frequently encountered in this patient group, causes a rise in coronary artery disease (CAD) frequency ${ }^{[20]}$. Studies performed in the pediatric age group in particular have shown a greater incidence of cardiomyopathy and congestive heart failure (CHF) in patients with focal segmental glomerulosclerosis (FSGS). Researchers suggest this may be related to immune mechanisms ${ }^{[21]}$.

This clinical study was carried out to assess the presence of fQRS in children with NS and also to evaluate the relationship between fQRS and myocardial functions.

This study included 60 subjects who were subdivided into 2 groups: The first group included 30 patients with nephrotic syndrome. The second group included 30 apparently healthy subjected.

In our study, the range for age of NS patients was 2-15 years with the median 4.5 , and the male represented about $(76.7 \%)$ of patients. There was no statistically significant difference between cases and control as regarding age and sex $(p>0.05)$. This result was in agreement with , Hooman et al., ${ }^{[22]}$ and Saleh et al., ${ }^{[23]}$ who found that there was no significant difference between patient and control group as regard age and sex. We found no significant difference in heart rate, BMI, systolic and diastolic blood pressure between patient group and control group. This came in agreement with Saleh et al., ${ }^{[23]}$ who found that there was no significant difference in systolic blood pressure and BMI between patient group and control group while he was disagreed with us as regard diastolic blood pressure because he found highly significant difference as regard to diastolic blood pressure.Also, Candan et al., (2014) found that there was no significant difference between patient and control group as regard BMI. But Hooman et al., ${ }^{[22]}$ found significant difference as regard BMI.On the other hand, Alpert et al. ${ }^{[24]}$ and Bagga et al. ${ }^{[25]}$ found significant increase in diastolic blood pressure in patient group than control group especially with steroid resistant NS. This could be due to long term steroid \pm cytotoxic therapy, and also due to increased susceptibility of development of chronic renal failure.Also, Qin et al., [3], Hooman et al., ${ }^{[22]}$ found that there was a statistically significant difference in systolic and diastolic blood pressure between patient group and control group while, Qin et al., ${ }^{[3]}$ found that there was no significant difference in heart rate.

Echocardiographic assessment was done for all study group including case and control. As regard structural Echocardiographic variable measurement, our study showed there was no significant difference between patient and control group as regard conventional echocardiographic parameters MPA, RPA, LPA, AO, LA, PW, TAPSE, LVDD, LVSD, but there was a statistically significant increase in IVS size in patient group in comparison to control group. This result was in disagreement with Saleh et al., ${ }^{[23]}$ who found that there was no significant difference between patient and control group as regard all conventional echocardiographic parameters including IVS. Assessment of left ventricular systolic function, in the present study showed that was no significant difference between case and control group as regard L.V Systolic function, this was agreement with Qin et al., ${ }^{[3]}$ who found that there was no significant difference between patient and control group as regard, LVEF. Assessment of left ventricular diastolic function, in our study showed that there was a significant decrease in $\mathrm{E}$ wave in patient than control group ( $\mathrm{p}$ value $=0.021$ ). This came in agreement with Saleh et al., ${ }^{[23]}$ who found that E-wave was decreased in patient group than in 


\section{Laila et al}

control group with a statistically significant difference $(\mathrm{p}$ value $=0.0001$. While there was no significant difference between patient and control group as regard A- wave and deceleration time of E-wave. This came in disagreement with Saleh et al., ${ }^{[23]}$ who found that there was a statistically significant difference between patient and control group as regard to A-wave and deceleration time of $\mathrm{E}$ wave. Doppler tissue imaging is concerning TDI systolic function, we found nonsignificant difference between case and control as regard peak systolic velocity ( $\mathrm{s}^{\prime}$ ) And also we used TDI velocities for assessment of LV diastolic function and found non-significant difference between case and control as regard ( $\left.E^{\prime}\right)$ and (a'). There are known to be many limitations to classic echocardiographic index evaluation of myocardial functions ${ }^{[11]}$. New techniques are therefore being developed in order to be able to better evaluate cardiac functions. One such is the Tei index ${ }^{[10]}$. Also known as the myocardial performance index, the Tei index is used in the analysis of myocardial systolic and diastolic functions ${ }^{[11]}$. In the present study there was no significant difference between patient and control group as regard to Tie index $(\mathrm{p}>0.05)$. This came in disagreement with Saleh et al., ${ }^{[23]}$ who found that there was a statistically significant difference between patient and control group as regard to Tie index ( $\mathrm{p}$ value $=0.045$ ).

Tei index, shown in previous studies was used to provide a better analysis than older echocardiographic indices, to analyze myocardial functions. Tei index is more sensitive than classic echocardiographic parameters, particularly in showing subclinical myocardial function compromise [19]. Fragmented QRS demonstrates scarred myocardium and is linked to ventricular dysfunction. In Coronary artery disease, fQRS represents previous myocardial infarction and is an independent predictor of adverse cardiac events ${ }^{[27]}$. In the present study, fQRS was present in $56.7 \%$ of patient group, and absent in the other $43.3 \%$ with a statistically significant increase in prescence in case than control. ( $p$ value $=0.003)$. Moreover, we think that the presence of fQRS in an NS patient group can be a marker of impaired myocardial performance. This came in agreement with Özkan et al., ${ }^{[19]}$ who that identified that fQRS at a level approaching $50 \%$ in NS patient group. So, we divided the cases group into two sub group according to presence of FQRS. There was no significant association between age, sex and BMI and presence of FQRS in ECG in patient with nephrotic syndrome. There was significant increase in systolic and diastolic blood pressure in patient with FQRS in ECG. This came in agreement with Litwin and Niemirska, ${ }^{[28]}$ who reported that these patients frequently have several additional risk factors, such as hypertension, obesity, insulin resistance, inflammation, long-term treatment with steroids and other immunosuppressive drugs, such as cyclosporine A, hypercoagulability, and oxidative stress. All of these risk factors may act in concert to produce atherosclerotic vascular lesions

There was no significant difference between patients with or without fQRS in Heart rate, kidney function tests, $\mathrm{Ca}, \mathrm{P}$, albumin, urinary protein or lipid parameters. This came in agreement with Özkan et al., ${ }^{[19]}$ who found that there were no demographic or biochemical factors affected incidence of fQRS, with the exception of proteinuria. fQRS incidence was higher in patients with a higher level of proteinuria. Clear proteinuria is today accepted as being related to a rise in incidence of cardiovascular events, for which reason they constitute one of the risk factors for cardiovascular events ${ }^{[29]}$. The median of protein excretion in 24-h urine in the patients with fQRS was $2028.62 \mathrm{mg} /$ day, compared to $1435.5 \mathrm{mg} /$ day for those without $(\mathrm{p}<0.05)$. Microalbuminuria is a marker of endothelial damage, which gives rise to inflammatory cascade activation. Proteinuria in NS patients causes inflammatory cytokine release during endothelial injury, tubular reabsorption and tubular catabolism ${ }^{[30]}$. In addition, malnutrition developing secondary to hypoalbuminemia leads to inflammatory cascade activation and 


\section{Laila et al}

cytokine release ${ }^{[31]}$. Studies have shown that inflammatory cytokines cause myocardial injury. Although inflammation markers could not be assessed, due to this being a crosssectional study, in the light of this information, one of the probable reasons for the relation between the fQRS and proteinuria may be a rise in inflammatory cytokines ${ }^{[4]}$. Previous studies have shown that $\mathrm{fQRS}$ is a predictor of cardiovascular events in a variety of populations ${ }^{[15]}$. The cardiovascular events increasing effect is thought to be associated with myocardial scarring and/or the presence of fibrosis, leading to nonhomogeneous myocardial electrical activity ${ }^{[7]}$. Indeed, studies have revealed that the presence of $f Q R S$ is correlated with cardiac structural abnormality, ventricular arrhythmia, myocardial scarring and fibrosis ${ }^{[8]}$. Also, Eddy and Symons, ${ }^{[32]}$ found that the duration of nephrotic dyslipidemia appears to be a critical factor for initiating vascular damage and, therefore, an increased risk of premature atherosclerosis exists in patients with unremitting NS. In the present study, there was no significant difference in TAPSE between patients with and without fQRS. This came in agreement with Özkan et al., ${ }^{[19]}$ who found that there was no significant difference in TAPSE, a right ventricle function marker. In the present study, there was no statistically significant predictor between ECHO parameter and FQRS. There was no significant difference between cases with and without FQRS as regard ECHO parameter and diastolic function. But there was significant decrease in systolic function (FS\%) and nonsignificant decrease in $(\mathrm{EF} \%)$ in cases with FQRS in ECG. This come in agreement with Özkan et al., ${ }^{[19]}$ who found that there was no significant difference in classic echocardiographic and diastolic function markers at echocardiographic examinations performed in order to assess the relationship between $\mathrm{fQRS}$ and myocardial functions. In the present study there was no statistically significant differences between tissue doppler parameter and Tie index with FQRS except for Em wave. On the other hand, Özkan et al., ${ }^{[19]}$

June 2019 Volume 25 Issue 3

\section{Zagazig University Medical Journals}

found that in terms of the association between fQRS and myocardial functions, a correlation was only determined between Tei index and fQRS. We perform univariant analysis for patient with FQRS and all parameter and detect FQRS was presented with increase in systolic and diastolic blood pressure, and in patient with systolic dysfunction (decrease FS\%), and in patient with diastolic dysfunction (E'). We identified fQRS at a level approaching $56.7 \%$ in this patient group, in which the presence of fQRS has not been investigated before. Presence of fQRS being not in relation with Tei index and no relation with other parameters being identified suggests that was because of low number of our patient in this study.

\section{CONCLUSION}

NS children generally have a high risk of cardiovascular complications. The present study revealed that $\mathrm{fQRS}$, determined using ECG, an economic and easily accessible technique, can be used as an early marker of myocardial function impairment in this patient group

\section{Declaration of interest}

The authors report no conflicts of interest. The authors alone are responsible for the content and writing of the paper.

\section{Funding information}

None declared

\section{REFERENCES}

1-Silva LS, Oliveira RA, Silva GB, et al Cardiovascular disease in patients with endstage renal disease on hemodialysis in a developing country. Saudi J Kidney Dis Transpl; (2012):23: 262-266.

2-Sinha A, and Bagga A Nephrotic Syndrome. Indian J Pediatr; (2012): 79:1045-1055.

3-Qin, Q., Xu, et al., Corrigendum to "evaluation of right ventricle function in children with primary nephrotic syndrome" [Pediatr Neonatol (2010): 51 :166-171

4-Moreira-Rodrigues M, RonconAlbuquerque $\mathbf{R}$ Jr, HenriquesCoelho T, et al. Cardiac remodeling and dysfunction in nephrotic syndrome. Kidney Int; (2007):71: 1240-1248.

5-Steger A, Sinnecker D, Berkefeld A, et al Fragmented QRS. Relevance in clinical www.zumj.journals.ekb.eg 416 


\section{Laila et al}

practice

Herzschrittmacherther

Elektrophysiol; (2015): 26(3):235-241.

6-Das MK, Khan B, Jacob $S$, et al Significance of a fragmented QRS complex versus a $\mathrm{Q}$ wave in patients with coronary artery disease. Circulation; (2006): 113: 2495-2501.

7-Das MK, Suradi H, Maskoun W, et al Fragmented wide QRS on a 12-lead ECG: a sign of myocardial scar and poor prognosis. Circ Arrhythm Electrophysiol; (2008): 1: 258-268.

8- Peters S, Trummel M, and Koehler B QRS fragmentation in standard ECG as a diagnostic marker of arrhythmogenic right ventricular dysplasia-cardiomyopathy. Heart Rhythm; 5(2008):: 1417-1421.

9-Sadeghi R, Dabbagh VR, Tayyebi M, et al Diagnostic value of fragmented QRS complex in myocardial scar detection: systematic review and meta-analysis of the literature. Kardiol Pol; (2016): 74(4):331337.

10- Tei C, Ling LH, Hodge DO, et al., New index of combined systolic and diastolic myocardial performance: a simple and reproducible measure of cardiac function-a study in normals and dilated cardiomyopathy. J Cardiol; (1995): 26: 357366.

11-Lakoumentas JA, Panou FK, Kotseroglou VK, et al The Tei index of myocardial performance: applications in cardiology. Hellenic J Cardiol; (2005): 46: 52-58.

12-Tin SS, and Wiwanitkit V Fragmented QRS and myocardial performance index in nephrotic syndrome. Anatol J Cardiol; (2015): 15(2): 161-161

13-Rosengarten JA, Scott PA, and Morgan JM Fragmented QRS for the prediction of sudden cardiac death: a meta-analysis. Europace; (2015): 17(6):969-977.

14-Akbarzadeh F, Pourafkari L, Ghaffari S, et al Predictive value of the fragmented QRS complex in 6-month mortality and morbidity following acute coronary syndrome. Int J Gen Med; (2013):6:399-404.
15-Das MK, and Zipes DP Fragmented QRS: a predictor of mortality and sudden cardiac death. Heart Rhythm; (2009): 6: 8-14.

16-Azat, N. F. A., \& Hasan, et al Triggering factors for relapses in steroid sensitive nephrotic syndrome. Int. J. Curr. Microbiol. App. Sci, (2016): 5(8): 842-851.

17-Feehally, J. Focal segmental glomerulosclerosis: challenges in definitions, pathogenesis and management. African Journal of Nephrology, (2017): 20(1): 48-56.

18-Nash, M.A.; Edelmann., et al., Minimal change nephrotic syndrome, diffuse mesengial hypercellularity and focal glomerulosclerosis. In: Edelmann CM (ed): Pediatric kidney disease. Boston, MA, Little Brown; (1992): 1272-1290.

19-Özkan, G., Adar, et al., Presence of fragmented QRS and its correlation with myocardial performance index in patients with nephrotic syndrome. Anadulu Kardiyoloji Dergisi: AKD, (2014): 14(5): 450.

20-Patnaik, S. K., Kumar, et al., Cardiovascular outcomes of Nephrotic syndrome in childhood (CVONS) study: a protocol for prospective cohort study. BMC nephrology, (2018): 19(1): 81.

21-Adedoyin O, Frank R, Vento S, et al., Cardiac disease in children with primary glomerular disorders-role of focal segmental glomerulosclerosis. Pediatr Nephrol; (2004): 19: 408-412.

22-Hooman, N., Isa-Tafreshi, et al., (2013): Carotid artery function in children with idiopathic nephrotic syndrome. Nefrologia, 33(5): 650-656.

23-Eddy AA, Symons JM Nephrotic syndrome in childhood. Lancet (2003): 362:629-639.

24- Alpert MA, Bauer JH, Parker BM, et al., Pulmonary hemodynamics in systemic hypertension. Long-term effect of minoxidil. Chest (1979): 76: 379-383.

25-Bagga A, Ali U, Banerjee $S$, et al. Management of steroid sensitive nephrotic syndrome. Indian Pediatr (2008): 45: 203211. 
26-Swiatecka-Urban, A., Woroniecki, R. P., \& Kaskel, et al., Nephrotic syndrome in pediatric patients. Frontiers Media SA. (2017):

27-Take, Y., \& Morita, et al., Fragmented QRS: what is the meaning? Indian pacing and electrophysiology journal, (2012): 12(5):213-225.

28- Litwin M, Niemirska A Intima-media thickness measurements in children with cardiovascular risk factors. Pediatr Nephrol (2009): 24:707-719

29-Tonelli M, Klarenbach SW, Lloyd AM, et al., Higher estimated glomerular filtration rates may be associated with increased risk of adverse outcomes, especially with concomitant proteinuria. Kidney Int; (2011): 80: 1306-1314.

30-Kim SY, Lim AY, Jeon SK, et al., Effects of dietary protein and fat contents on renal function and inflammatory cytokines in rats with adriamycin-induced nephrotic syndrome. Mediators Inflamm 2011.

31-Kraut, J. A., \& Madias, et al., Adverse effects of the metabolic acidosis of chronic kidney disease. Advances in chronic kidney disease, (2017): 24(5): 289-297.

32-Eddy AA, Symons JM Nephrotic syndrome in childhood. Lancet (2003): 362:629-639.

To cite this article: Abd Elaziz LR, Abouzeid HM, Abu Fares KY. Myocardial Dysfunction in Children with
Nephrotic Syndrome, A Tissue Doppler Study .,Egypt.ZUMJ 2019;25(3);409-418,DOI:
$\begin{aligned} & \text { 10.21608/zumj.2019.9621.1060 } \\ & \text { a }\end{aligned}$

